\title{
DESENVOLVIMENTO DE AÇOS RESISTENTES À ABRASÃO ATRAVÉS DA TECNOLOGIA DE TÊMPERA DIRETA NA LAMINAÇÃO DE CHAPAS GROSSAS DA GERDAU OURO BRANCO*
}

\section{Resumo}

\author{
Rafael Abreu Fraga ${ }^{1}$ \\ Jose Herbert Dolabela da Silveira ${ }^{2}$ \\ Romeu Thomaz Viana Júnior ${ }^{3}$ \\ Emanuelle Garcia Reis ${ }^{4}$ \\ Rodney Pardo Alves ${ }^{5}$ \\ Maurício Martins Pereira ${ }^{6}$
}

Foram avaliados os efeitos da tecnologia de laminação seguida da têmpera direta na produção de chapas grossas de alta dureza, resistentes à abrasão, na Linha de Chapas Grossas da Gerdau Ouro Branco. Para tanto, foram analisados os parâmetros de processo e propriedades mecânicas, através da realização de ensaios de dureza, tração, tenacidade ao impacto Charpy e metalografia. A tecnologia de têmpera direta, realizada através do Mulpic, possibilita a fabricação de aços de alta dureza com carbono equivalente significativamente baixo. O mecanismo principal para aumento da dureza, baseia-se em uma laminação com passes de alta redução, iniciando o resfriamento com o aço ainda constituído exclusivamente pela fase austenítica, sendo temperado a baixas temperaturas, ocorrendo a completa transformação martensítica. Tanto o processo de têmpera direta no Mulpic, quanto os processos anteriores precisam ser muito bem controlados, visando uma microestrutura homogênea e um produto com a planicidade adequada.

Palavras-chave: Mulpic; Têmpera Direta; Chapas Grossas; Resistente à Abrasão.

\section{DEVELOPMENT OF WEAR RESISTANT STEELS THROUGH DIRECT QUENCHING TECHNOLOGY AT GERDAU OURO BRANCO PLATE MILL}

\begin{abstract}
In this paper, the effects of the rolling technology followed by the direct quenching in the production of high hardness plates, wear resistant, in Ouro Branco Gerdau Plate Mill plant were evaluated. For that, the process parameters and mechanical properties were analyzed through hardness tests, tensile strength, impact toughness and metallography. The direct quench technology, made through the Mulpic, enables the fabrication of high hardness steels with significantly reduced carbon equivalent. The main mechanism to increase hardness is based rolling with high reduction passes, starting cooling with the steel still constituted exclusively by the austenitic phase, being quenched at low temperatures, occurring the complete martensitic transformation. Both the direct quench process at the Mulpic and the previous processes must be well controlled, aiming a homogeneous microstructure and a product with adequate flatness.
\end{abstract}

Keywords: Mulpic; Direct Quenching; Plate Mill; Wear Resistant.

1 Engenheiro Metalúrgico, Assessor Técnico de Laminação, Laminação de Chapas Grossas, Gerdau, Ouro Branco, MG, Brasil.

2 Engenheiro Metalúrgico, Mestre, Gerente da Laminação de Chapas Grosas, Laminação de Chapas Grossas, Gerdau, Ouro Branco, MG, Brasil.

3 Engenheiro Metalúrgico, Assessor Técnico de Processos e Produtos, Pesquisa e Desenvolvimento de Aços Planos, Gerdau, Ouro Branco, MG, Brasil.

4 Engenheira Civil, Mestre, Assessor Técnico de Laminação, Laminação de Chapas Grossas, Gerdau, Ouro Branco, MG, Brasil.

5 Engenheiro Metalúrgico, Chefe da Linha de Laminação de Chapas Grossas, Laminação de Chapas Grossas, Gerdau, Ouro Branco, MG, Brasil.

6 Engenheiro Metalúrgico, Assessor Técnico de Laminação, Laminação de Chapas Grossas, Gerdau, Ouro Branco, MG, Brasil. 


\section{INTRODUÇÃO}

Equipamentos pesados como tratores, retroescavadeiras, caçambas de caminhões fora de estrada, tremonhas, revestimentos de calhas, transportadores de minérios, peças de altos-fornos e ventiladores industriais são suscetíveis a uma quantidade significativa de desgaste e corrosão, destacando que o custo de degradação do material representa uma proporção considerável dos custos operacionais. Aços resistentes à abrasão com adições de elementos de liga e temperados, permitem atender critérios de maior vida útil e produtividade, com menos tempo de inatividade para os equipamentos, tendo como principal característica a alta dureza [1]. Estes materiais apresentam dureza Brinell na faixa de 360 a 550 e devem ter boa soldabilidade e, em alguns casos, boa tenacidade.

$\mathrm{O}$ alto e crescente custo para substituir peças suscetíveis ao desgastadas representa um desafio contínuo para o desenvolvimento de materiais. Projetos de peças de desgaste devem em primeiro lugar prever resistência adequada à abrasão, no entanto, frequentemente, também devem ter a capacidade de resistir ao impacto e à corrosão.

No presente trabalho será apresentada a tecnologia de têmpera direta que permitirá atender os melhores critérios de maior vida útil e menor tempo de inatividade [1].

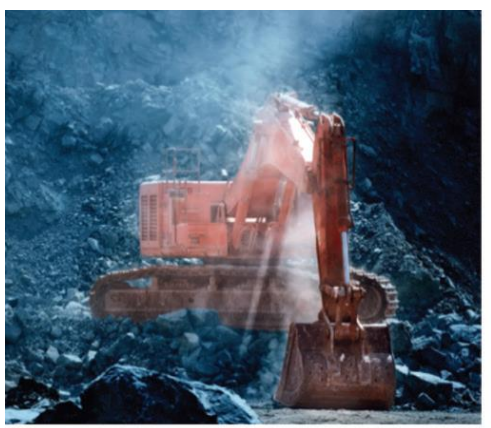

(a)

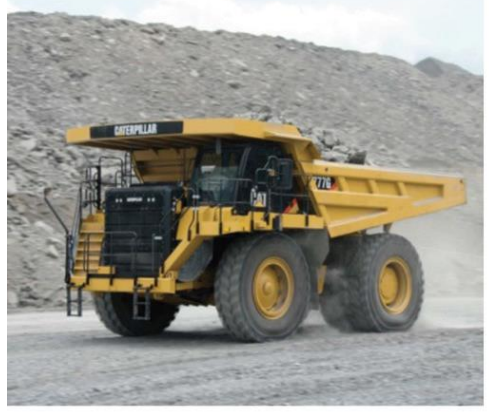

(c)

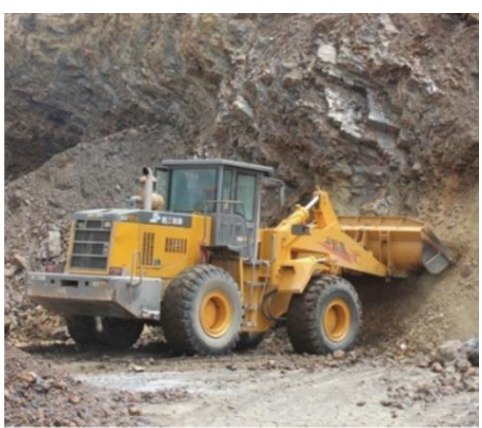

(b)

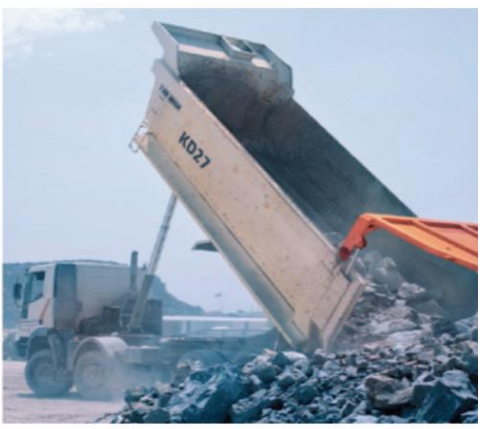

(d)

Figura 1. Exemplo de equipamentos em operação: (a) Escavadora, (b) Retro escavadeira, (c) Caminhão fora de estrada e, (d) caminhão basculante [1].

A abrasão é uma forma de desgaste que ocasionada por partículas duras de diversos tamanhos. Enquanto a severidade da abrasão aumenta à medida que a dureza das partículas aumenta, o desgaste abrasivo não é necessariamente eliminado se as partículas forem mais macias. No caso de industrias, como a mineração, o processamento mineral ocorre com misturas sólido-líquido, assim, partículas abrasivas podem afetar as taxas de corrosão removendo filmes protetores 
e expondo o metal fresco ao meio ambiente, combinado o efeito de abrasão e corrosão [1].

\subsection{Aços Resistentes à Abrasão}

Aços resistentes à abrasão são projetados para suportar o desgaste causado pelo atrito ou pelo impacto de materiais como minerais, areia ou cascalho. A resistência à abrasão geralmente aumenta com a dureza, evitando arranhões ao ser atingido por partículas duras. A resistência à fadiga e a resistência são propriedades adicionais necessárias, especialmente quando existirem cargas dinâmicas ou de impacto. Além disso, algumas aplicações podem exigir resistência à temperatura e à oxidação. Consequentemente, os tipos de aços resistentes à abrasão são normalmente classificados com base nos seus níveis de dureza que variam de 300 a 600 HB. A classe padrão enfoca principalmente a dureza da superfície e é representada por aços C-Mn não ligados. Os graus de aço ligado combinam dureza com garantia de tenacidade e também permitem produzir chapas mais espessas, especialmente os de baixo carbono equivalente, que proporcionam boa tenacidade a temperaturas mais baixas e simultaneamente melhoram a soldabilidade. A composição química dos aços resistentes à abrasão é geralmente adaptada para obter propriedades mecânicas requeridas para sua aplicação. Geralmente compreendem um teor de carbono de aproximadamente $0,20 \%$ em peso e teor de manganês inferior a 2,0\% em peso. Estes aços podem também conter certos elementos de liga tais como cromo, níquel, molibdénio e / ou boro que retardam a cinética de transformação da austenita em ferrita e, consequentemente, aumentam a temperabilidade [2].

\subsection{Influência da Microestrutura na Resistência à Abrasão}

A microestrutura do aço desempenha um papel crítico em relação ao seu desempenho de desgaste. Para a mesma dureza, a austenita é mais resistente à abrasão do que a ferrita, a perlita ou a martensita, devido à maior capacidade de encruamento e ductilidade da austenita [3]. Em aços com menos de 1,0\% de carbono, as microestruturas bainíticas possuem a maior resistência ao desgaste, seguidas de microestruturas temperadas e revenidas, estruturas recozidas e estruturas esferoidizadas, todas com o mesmo nível de dureza [4]. A Figura 2 resume os efeitos da dureza do aço e das microestruturas na resistência ao desgaste [5].

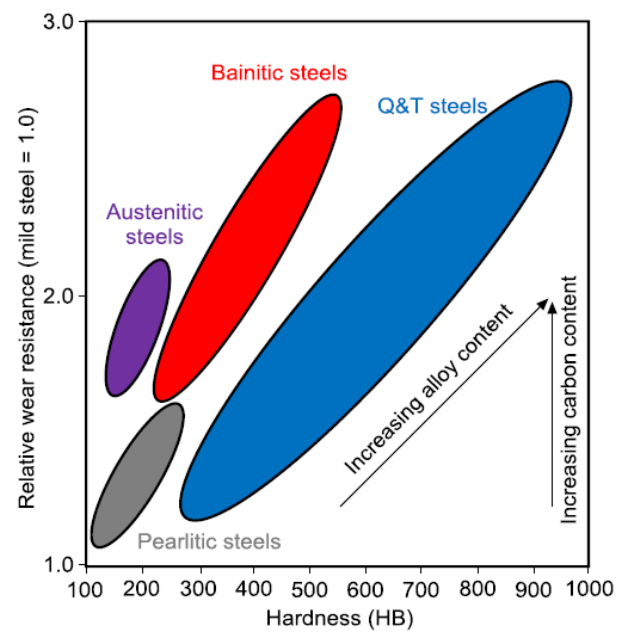


Figura 2. Influência da microestrutura e dureza na resistência ao desgaste de vários tipos de aços A Figura 3 mostra a relação entre a dureza e a razão de resistência à abrasão, de acordo com ASTM G65 utilizando sílica (SiO2) como o abrasivo, onde é calculada a perda de peso do aço [6].

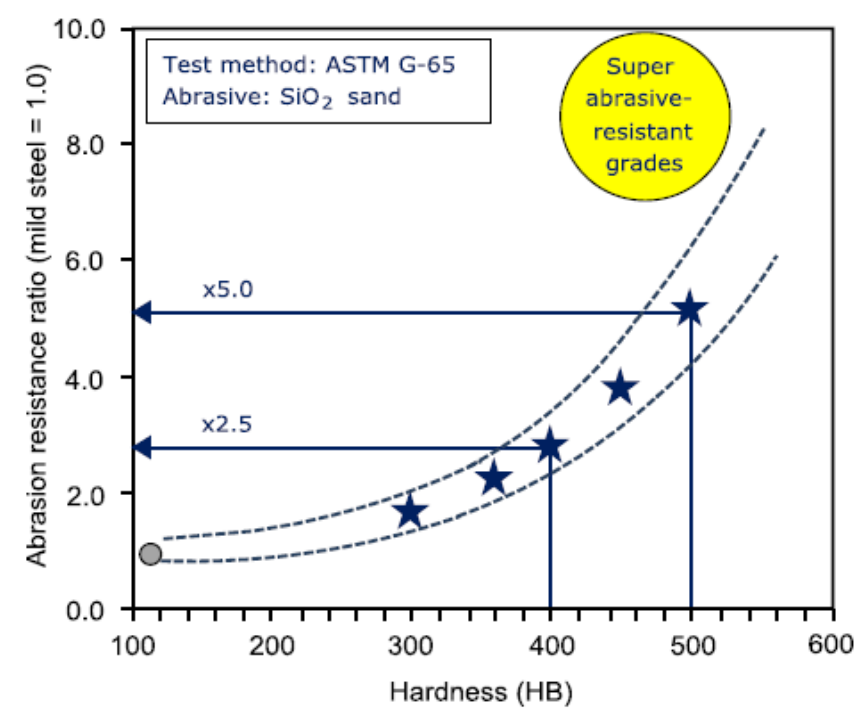

Figura 3. Desempenho de aços resistentes à abrasão típicos e potencial de graus super-resistentes à abrasão.

Conforme ilustrado na Figura 4, o aumento da dureza numa microestrutura ferrítaperlíta resulta apenas numa pequena melhoria da resistência ao desgaste. No aço martensítico, pelo contrário, o aumento da dureza leva a ganhos substanciais na resistência ao desgaste. Esta diferença parece ser a conseqüência de diferentes mecanismos de desgaste atuando em ambos os aços. A fase ferrita macia presente no aço ferrítico-perlítico é deformada plasticamente pela indentação de partículas duras na região próxima à superfície, levando ao encruamento (Figura 5). A fadiga de baixo ciclo pode induzir trincas na zona endurecida e retirando as partículas.

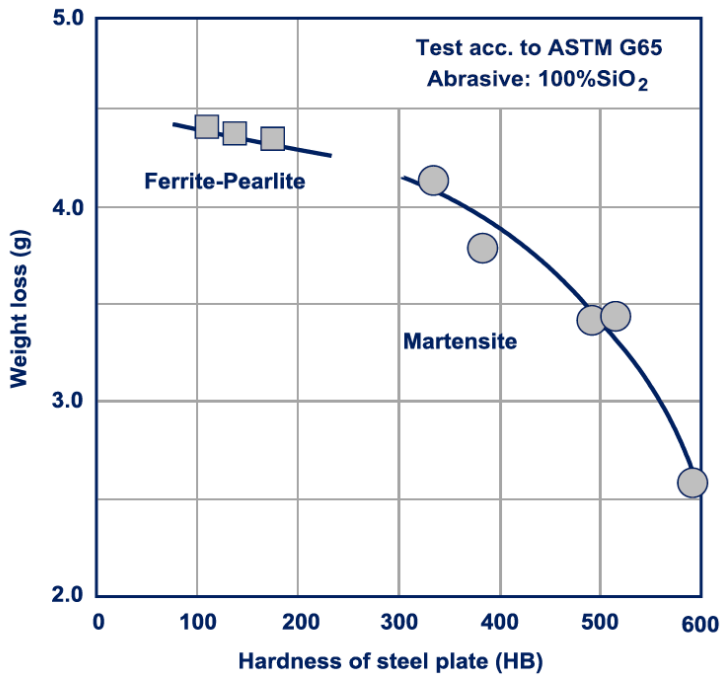

Figura 4: Relação entre dureza, microestrutura e perda de peso no teste de roda de borracha. 
Ferritic-Pearlitic steel (HV100-200)

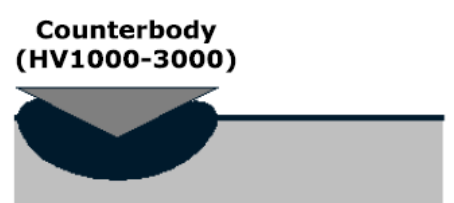

Work hardening

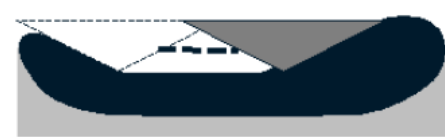

low-cycle fatigue

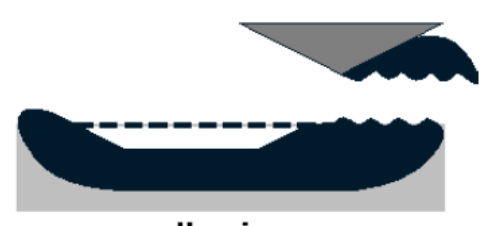

adhesion

Martensitic steel (HV300-600)

Counterbody (HV1000-3000)

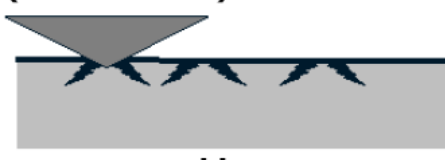

cracking

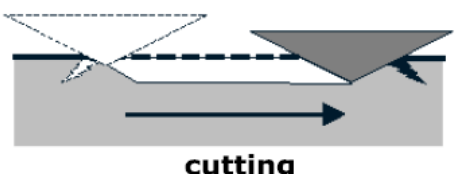

cutting

Figura 5. Mecanismos esquemáticos de desgaste de partículas duras em aços ferrítico-perlítico e martensítico.

O aço martensítico temperado tem uma dureza muito elevada e não inclui a presença de uma fase macia deformável. Após indentação de partículas duras na superfície de aço martensítico, micro-trincas podem formar. Quando várias microtrincas adjacentes se ligam, uma partícula de desgaste pode se soltar. Vários efeitos estão disponíveis para aumentar a resistência contra este mecanismo de desgaste baseado em trincamento:

1 - Aumentar a dureza do aço aumenta a tensão de limite elástico do material, reduzindo a formação de trincas.

2 - Refinar a microestrutura obstrui a propagação das trincas existentes, em particular, aumentando o número de contornos de grão de alto ângulo.

3 - A incorporação de fases de carbonetos especiais ultra-duros na matriz martensítica pode absorver as maiores tensões de contato sem fraturar. É importante que o tamanho destas fases de carboneto seja suficientemente grande em comparação com o tamanho do corpo abrasivo para evitar que sejam removidas por arrancamento de partículas. A fase dura pode consistir em carbonetos de molibdênio ou de cromo formados durante o revenimento, bem como de carbonetos de nióbio ou de titânio primários que se formaram antes da laminação.

\section{MATERIAIS E MÉTODOS}

O material de referência é um aço micro ligado, ao $\mathrm{Nb}, \mathrm{V}, \mathrm{Ti}, \mathrm{B}, \mathrm{Cr}$, visando obter uma dureza Brinnel de $450 \mathrm{HB}$. As placas foram produzidas na linha de Chapas Grossas da planta da Gerdau em Ouro Branco. As especificações de composição química para atender esse graus de aço está apresentada na Tabelas 1 abaixo:.

Tabela 1. Composição química utilizada

\begin{tabular}{c|c|c|c|c|c|c|c|c|c|c|c}
\hline $\mathbf{C}$ & $\mathbf{M n}$ & $\mathbf{S i}$ & $\mathbf{P}$ & $\mathbf{S}$ & $\mathbf{A l}$ & $\mathbf{N b}$ & $\mathbf{T i}$ & $\mathbf{V}$ & $\mathbf{B}$ & $\mathbf{C r}$ & $\mathbf{C e q}$ \\
\hline$\leq$ & $\leq$ & $0,1 \mathrm{a}$ & $\leq$ & $\leq$ & $\geq$ & $\leq$ & $\leq$ & $\leq$ & $\leq$ & $\leq$ & $\leq$ \\
0,22 & 1,60 & 0,5 & 0,035 & 0,035 & 0,015 & 0,05 & 0,05 & 0,10 & 0,004 & 0,40 & 0,52 \\
\hline
\end{tabular}


As placas foram obtidas por práticas de refino secundário e lingotamento contínuo, sendo que o aço foi processado por laminação controlada seguida da têmpera direta no Mulpic, resultando em chapas de $19 \mathrm{~mm}$ de espessura, conforme os parâmetros de definidos na tabela 2 :

Tabela 2. Parâmetros de processo

\begin{tabular}{l|l|l}
\hline Processo & Parâmetros & $\geq 250$ minutos \\
\hline \multirow{2}{*}{ Forno } & Tempo de permanência & $\geq 1200^{\circ} \mathrm{C}$ \\
\cline { 2 - 3 } & Temperatura de desenfornamento & $\geq 800^{\circ} \mathrm{C}$ \\
\hline \multirow{2}{*}{ Laminador } & Temperatura antes do último passe & $\geq 800^{\circ} \mathrm{C}$ \\
\hline \multirow{2}{*}{ Mulc } & Temperatura de início de resfriamento & $\leq 450^{\circ} \mathrm{C}$ \\
\cline { 2 - 3 } & Temperatura final de resfriamento & $\geq 30^{\circ} \mathrm{C} / \mathrm{seg}$ \\
\cline { 2 - 3 } & Taxa de Resfriamento $(12 \sim 25,4 \mathrm{~mm})$ & \\
\hline
\end{tabular}

Foram analisadas as propriedades mecânicas de chapas visando atender as propriedades conforme especificado na tabela 3:

\begin{tabular}{|c|c|c|c|c|}
\hline Dureza (HB) & $\sigma_{e}(\mathrm{MPa})$ & $\sigma_{R}(\mathrm{MPa})$ & $e_{t}(\%)$ & Along. (\%) \\
\hline $410-490$ & $>900$ & $>1000$ & 90 & $>10$ \\
\hline
\end{tabular}

A dureza foi determinada a $0,75 \mathrm{~mm}$ e $1.50 \mathrm{~mm}$ da superfície nas duas faces das amostras, com carga de $3000 \mathrm{kgf}$. A microdureza foi determinada com carga de $1000 \mathrm{~g}$ em vários pontos ao longo da espessura das amostras, onde os resultados foram convertidos para HB conforme Norma ASTM A370. Os ensaios de tração foram realizados na direção transversal à da laminação. As análises metalográficas dos cps foram realizadas em seções longitudinais, a aproximadamente $1 / 4$ da espessura. As microestruturas foram analisadas por microscopia ótica após ataque com reagente químico nital $3 \%$.

\section{RESULTADOS E DISCUSSÃO}

A composição química resultante está conforme as melhores práticas de produtores de aços resistentes à abrasão. Com o carbono equivalente encontrado, espera-se que o aço produzido apresentará boa soldabilidade de acordo com a sua aplicação. A Tabela 4 mostra os valores médios de carbono equivalente obtidos no material produzido industrialmente.

Tabela 4. Valores médios de Ceq(a) para os aços em estudo (\% em peso)

\begin{tabular}{c|c}
\hline Ceq especificado & Ceq obtido \\
\hline$\leq 0,52$ & 0,49 \\
\hline Ceq(IIW $)=C+M n / 6+(\mathrm{Cr}+\mathrm{Mo}+\mathrm{V}) / 5+(\mathrm{Ni}+\mathrm{Cu}) / 15$ &
\end{tabular}

O processo de reaquecimento das placas, laminação e têmpera direta, foram realizados seguindo parâmetros rigorosos de processo, com isso, foi possível obter chapas com boa distribuição de temperatura durante todo o processo. A figura abaixo apresenta um exemplo de imagem termográfica do esboço antes e após o processo de têmpera direta no Mulpic, demonstrando homogeneidade de temperatura durante todo o processo: 


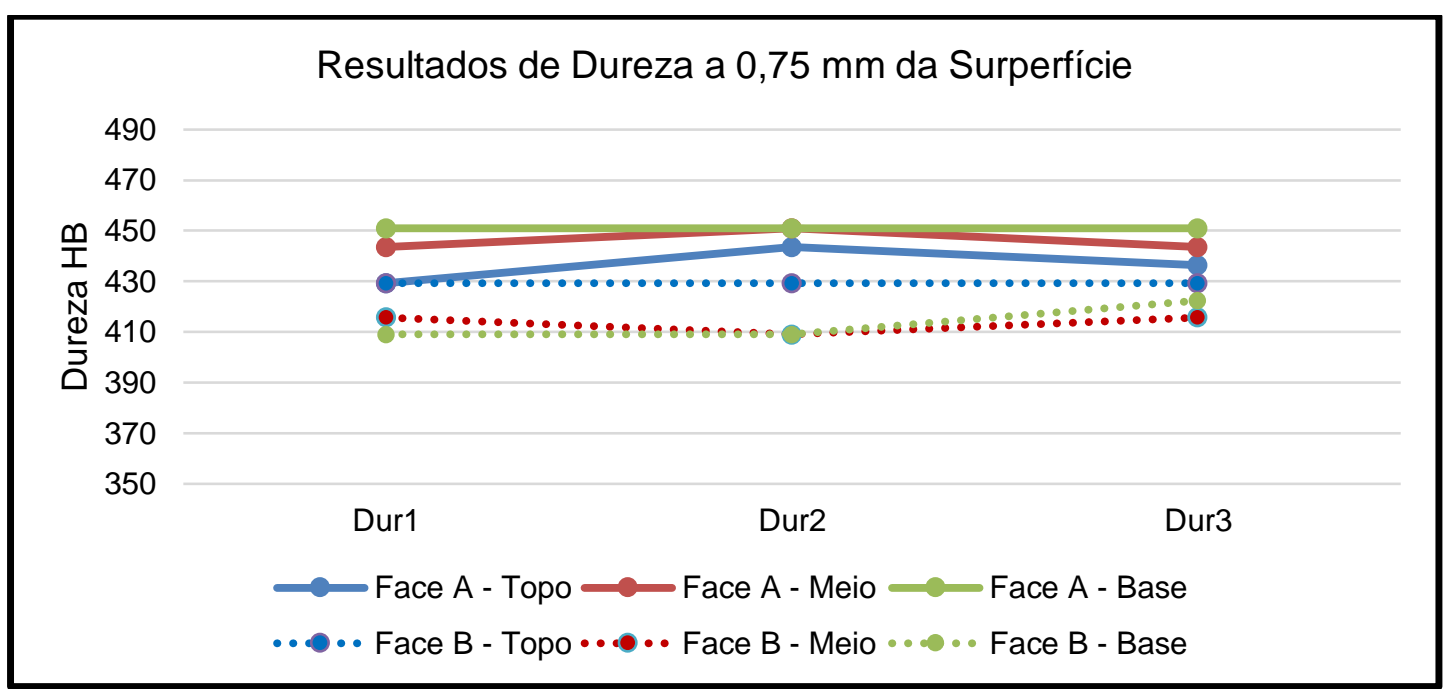

Figura 7. Variação de Dureza à 0,7 mm da superfície da amostra

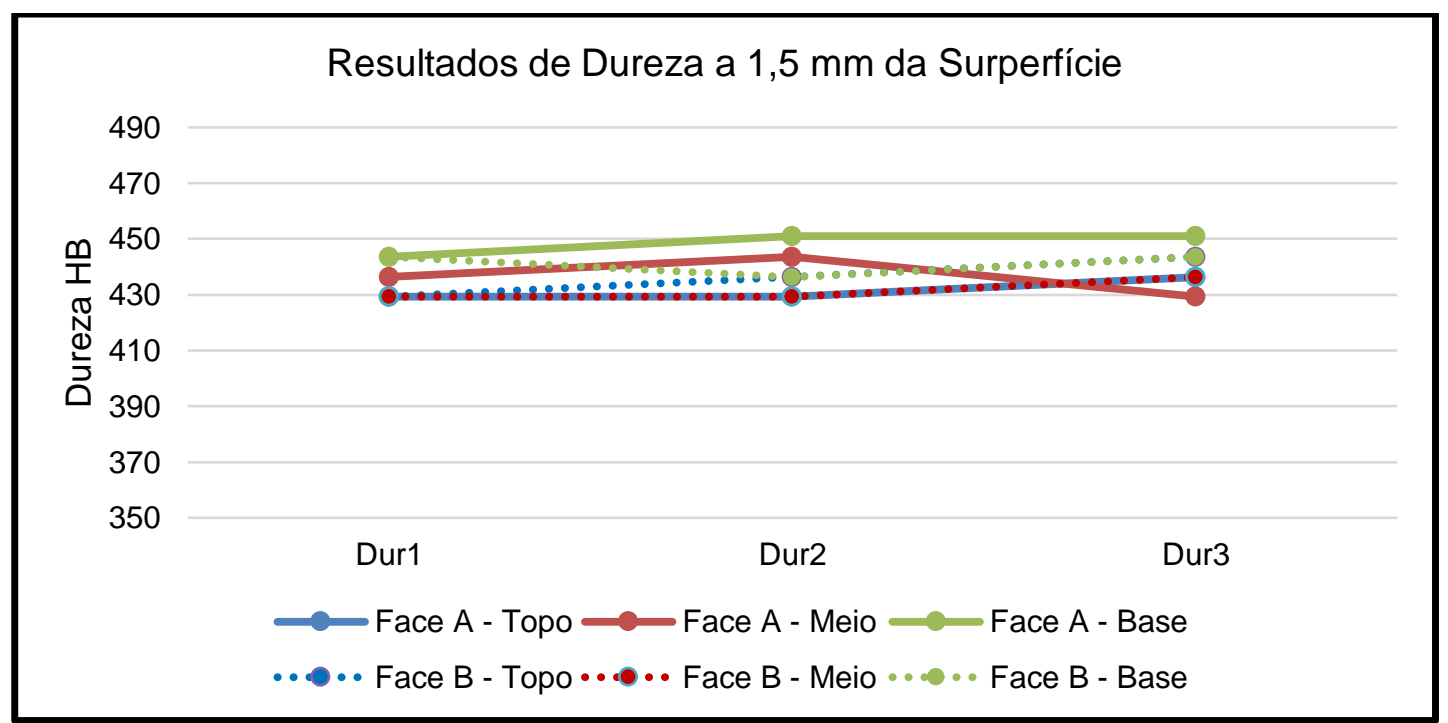

Figura 8. Variação de Dureza à 1,5 mm da superfície da amostra

A figura 8 mostra os resultados da dureza e os pontos onde o ensaio foi realizado em relação à espessura das amostras.

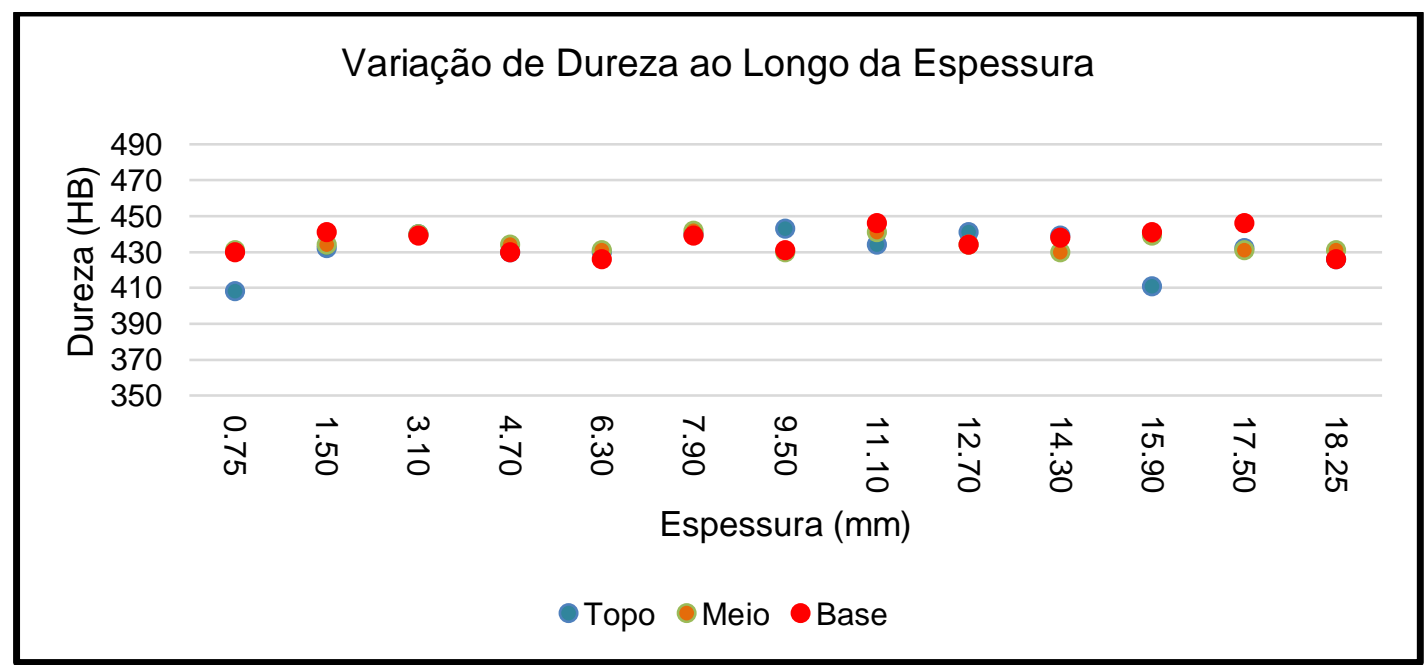

Figura 8. Variação de Dureza ao longo da espessura 


\subsection{Ensaio de Tração}

Geralmente a aplicação de aços resistentes ao desgaste não requerem resultados do ensaio de tração, porém é interesse dos clientes conhecerem estes valores. A tabela 5 apresenta os resultados do ensaio de tração:

Tabela 5. Resultados dos ensaios de tração tranversal

\begin{tabular}{c|c|c|c|c}
\hline Parâmetro & $\sigma_{\mathrm{e}}(\mathrm{MPa})$ & $\sigma_{\mathrm{R}}(\mathrm{MPa})$ & LE/LR $(\%)$ & Along. (\%) \\
\hline Média & 1180 & 1500 & 79 & 14 \\
\hline Desvio Padrão & 42 & 26 & 3 & 1,6 \\
\hline Mínimo & 1107 & 1461 & 74 & 12 \\
\hline Máximo & 1216 & 1536 & 82 & 16 \\
\hline
\end{tabular}

\subsection{Microestrutura}

Após seccionamento, seguido de preparação metalográfica e ataque químico com nital 3\%, ficou evidenciado que a estrutura básica da amostra é constituída de martensita. A figura 9 ilustra a microestrutura da amostra:

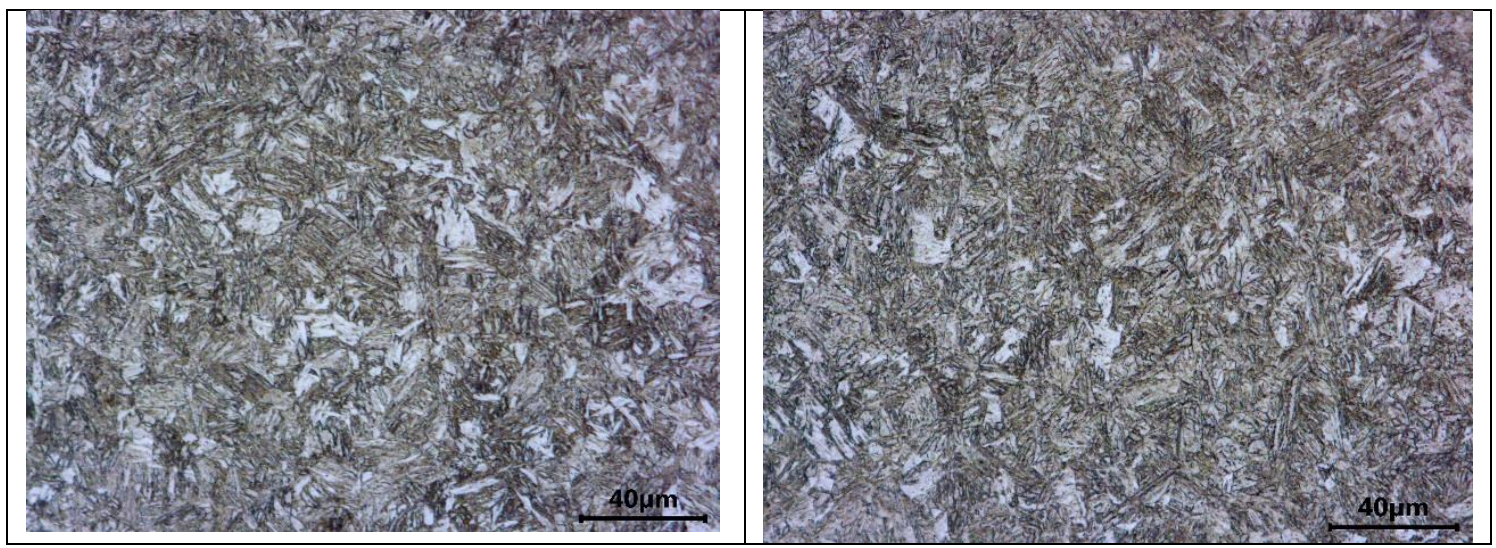

Figura 9. Microestrutura das amostras a 1/4 da espessura.

\section{CONCLUSÃo}

O Mulpic, equipamento que realiza o processo de têmpera direta, na Gerdau, Usina de Ouro Branco, mostrou-se com plena capacidade para produzir aços resistentes ao desgaste, da classe de $450 \mathrm{HB}$ e inferiores.

A boa performance do equipamento e os resultados obtidos, indicam que é possível desenvolver aços com dureza acima de $450 \mathrm{HB}$.

\section{REFERÊNCIAS}

1 Hazra, Sujoy S. Niobium-microalloyed Steels for Mining Equipments. Dezembro de 2014, Vol. 58, 7, pp. 145-150.

2 Mohrbacher, H. e Jarreta, D. Technology, Properties and Applications of Niobium Carbide Reinforced Steel and Iron Alloys. [ed.] Hardy Mohrbacher. Fundamentals and Applications of Mo and Nb Alloying in High Performance Steels. 1, 24-26 de Abril de 2015, Vol. 2, 1, pp. 227-256. 
3 J.H. Tylczak, "Effect of Material Properties on Abrasive Wear" ASM Handbooks Online, volume 18, Friction, Lubrication and Wear Technology, (Materials Park, OH: ASM International, 2002).

4 L. Xu and N.F. Kennon, "A Study of the Abrasive Wear of Carbon Steels," Wear, 148 (August 1991), 101-112.

5 K-H. Zum Gahr, Microstructure and Wear of Materials, (Amsterdam, Netherlands: Elsevier Science Publishers, 1987), 132-292.

6 Anon. "Abrasion-resistant Steels Plates of JFE Steel" (JFE Technical Report No. 11, June 2008), 26-28. 